\title{
Advantages of iodopolymer drugs to improve metabolism in cows
}

\author{
Alexey Yevglevsky ${ }^{*}$, Natalia Vanina $^{2}$, Sergey Shuklin ${ }^{2}$, and Artem Chvykov ${ }^{2}$ \\ ${ }^{1}$ Kursk Federal Agrarian Scientific Center, 10 Cheryomushki village, Kursk, Russia, +79192107160. \\ ${ }^{2}$ Kursk State Agricultural Academy named after I. I. Ivanov", 70 Karl Marks Street, Kursk, Russia
}

\begin{abstract}
Nowadays the usage of iodine medications for the correction of biochemical processes in industrial farming becomes more and more popular. The problem is that total iodine deficiency leads to the failure of normal production of thyroid hormones, which control all types of metabolism: protein, fat, carbohydrate, macro- and microelement, energy. In this regard, thyroid gland transgression comes with the development of severe pathologic biochemical processes, the clinical manifestation of pathophysiological conditions. Highly productive dairy cows are most vulnerable to iodine deficiency during lactation. This is connected with the fact that iodine is intensively released with milk. It is no coincidence that this fact is actively used for naturally iodized milk production. This can be achieved by feeding lactating cows with iodized salt separately or as part of feed additives. It is time to take into account that iodine deficiency of cows is most often manifested by joint pathology with the development of arthritis and arthrosis, pregnancy pathology and impaired reproductive function. Besides, cows' iodine deficiency reduces the productivity, fat content of milk, weight and fatness. We aim to highlight the problem of cows' iodine deficiency for managers and specialists of livestock farms. That is why we present the results of clinical studies on the injectable use of an iodized energy-metabolic composition based on an iodine polymer complex, known in pharmacology as iodinol and succinic acid. In our studies, it was found that the injectable use of the original iodine metabolic composition of cows during intensive lipolysis and protein overfeed provided an effective correction of the energy-metabolic process.
\end{abstract}

\section{Introduction}

Numerous biochemical studies and clinical observations indicate that the main reason for the premature retirement of highly productive cows is the rapid development of the biochemical process, fraught with the form of metabolic acidosis and ketoacidosis with a violation of protein, fat and carbohydrate metabolism [13].

Currently, there is a large variety of different types of metabolic stimulants, hepatoprotectors, biologically active additives, energy drinks for the correction of pathologic biochemical processes and prevention of pathophysiological conditions. This medication complex includes the composition and certain biologically active components. Such a formula is due to the complex mechanism of pathologic biochemical processes development. However, the inclusion of a biologically active component in the composition of complex medications is not always understandable and justified.

Almost all complex metabolic medications in humane medicine have numerous side effects and contraindications. In veterinary medicine, the side effects of drugs belonging to the class of metabolites are not so significant, but the therapeutic effectiveness could be better. One of the reasons of the low effectiveness of such medications is iodine deficiency. Until recently, the possibility of using iodine drugs for the correction of pathologic biochemical processes in industrial animal husbandry has not been practically paid attention to $[4,5]$.

Iodinol is a hydrous solution consisting of iodine $(0.1 \%)$, potassium iodide $(0.9 \%)$, polyvinyl alcohol [10]. Iodinol, unlike elemental iodine, is low toxic [10].

As a justification for the preparation and application of an energy-metabolic composition, we consider it is appropriate to give the following arguments. The preparation of iodinol is an aqueous solution consisting of iodine $(0.1 \%)$, potassium iodide $(0.9 \%)$, polyvinyl alcohol [10]. Iodinol, in contrast to elemental iodine, is low toxic, has antiviral, antimicrobial and antifungal activity [10]. Since 1960, when the drug "Iodinol" was officially registered by the Pharmaceutical Committee of the USSR, a huge clinical experience in the usage of iodinol in medicine and veterinary medicine has been accumulated. Many people are still surprised by the truly unique therapeutic effectiveness of the usage of iodinol in infectious and non-infectious pathology. Taking into account that iodinol does not irritate the mucous membranes, this determines the possibility of its injectable usage. It should be noted that the inventor of iodinol, V. O. Mokhnach, was the first to admit the possibility of using iodinol not only orally or externally, but also subcutaneously, intramuscularly, intravenously. It stimulated expanding the scope of clinical usage of the drug "Iodinol".

\footnotetext{
Corresponding author: evgl46@yandex.ru
} 
In turn, the unique spectrum of the metabolic action of succinic acid predetermined the possibility of its usage as a metabolic component. Succinic acid is a powerful stimulator of the metabolism of a living cell. Succinic acid influences cells and tissues that are in a state of excitation or pathologically altered. The stimulating effect of succinic acid is particularly pronounced in the weakening of the body and its disease. The absolute harmlessness of succinic acid and its salts (succinates), its ability to have a positive effect even at very low dosages $(10 \mathrm{mg} / \mathrm{kg})$ make it a very valuable component in the development of a new generation of so-called "smart" drugs, food and feed additives $[4,11,15,16]$.

Currently, it is a universal component that is widely used to improve the pharmacological activity of drugs $[4,11]$.

Working in this direction for many years, we have accumulated extensive experience in iodinol usage for the qualitative improvement of a number of well-known veterinary drugs that have side effects or contraindications. In our studies, it was found that the inclusion of succinic acid in the composition of iodinol in an amount of $1 \%$ or sodium succinate with a similar concentration of succinic acid allowed us to qualitatively improve its pharmacological properties. It particularly enhances iodinol metabolic activity, which was embodied in the implementation of a whole series of author's scientific developments. One of them is presented in this report.

The aim of our research is to evaluate the effectiveness of the usage of the iodine metabolic composition based on the iodine polymer complex with succinic acid for the metabolism correction of highly productive cows.

\section{Materials and methods}

The object of the research is highly productive cows (milk productivity is $6300-6500 \mathrm{~kg}$ of milk per cow) of the dairy unit of the instructional farm "Znamensky" of Kursk Agricultural Academy.

The iodinol combination containing $1 \%$ of succinic acid ( $1 \mathrm{~g}$ of acid per $100 \mathrm{ml}$ of iodinol) was used as iodine metabolic medication. Pharmacopoeial iodinol was used as a sample.

The medication was injected intramuscularly on the second-third day after calving and then it was injected every 7 days in the standard dosage of $10 \mathrm{ml}$ for cows.

Biochemical blood tests were performed using an automatic analyzer "BioChem FC-200". Blood sampling was carried out from the groups of 9 cows with the closest background indicators.

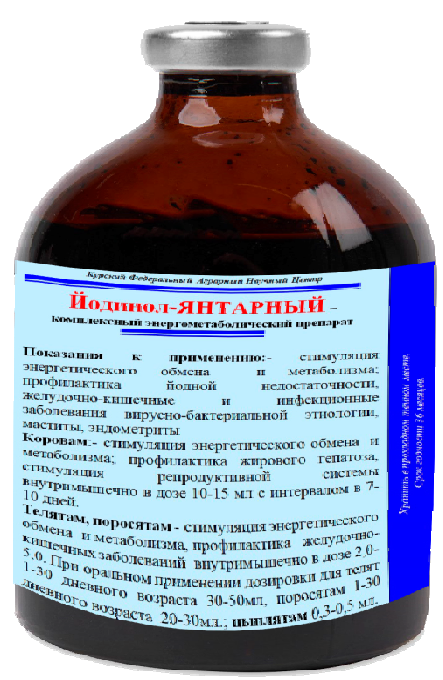

Fig. 2. Iodinol-succinic energy-metabolic preparation.

\section{Results and discussion}

During the clinical observations, we could find no side effects of IM pushing of energy-metabolic composition and pharmacopoeial iodinol. However, at the time of pushing, some animals had a slightly increased painful reaction. No swelling was formed at the injection site. This indicated that there was no irritating effect of the medication. It should be noted that the inventor of "Iodinol", V. O. Mokhnach, in the course of experiments established that iodine and iodides in the composition of high polymers, particularly with starch or polyvinyl alcohol, lose their irritating effect on tissues. Actually, he was the first who admitted the possibility of using iodinol not only internally or externally, but also subcutaneously, intramuscularly, intravenously. V. O. Mokhnach laid the foundation for expanding the scope of clinical usage of iodinol by this fact. No significant changes in the clinical status of the animals were detected until fawning.

Visible clinical changes began to appear in $10-15$ days after fawning. As it was expected, these changes were most obvious among the control group of cows. Their weight began rapidly to decrease. This indicated an intensive involvement of the fat reserves of the body in the metabolism process. In the process of glucogenesis, fats in the liver are converted into glucose, which is the main source of energy. The danger is that the body of high-dairy cows is able to use a very large amount of fat quickly - up to $60 \mathrm{~kg}$ [12]. This is about 1$2 \mathrm{~kg}$ per day. With such an intensive involvement in the energy process of fats, some of them do not have time to be metabolized and are deposited in the liver cells, as a result of which all metabolic processes, including the energy activity of mitochondria, are reduced in it. Finally, it can completely lose its metabolic and detoxification function, which leads to the liver coma and causes the death of the animal. In this regard, the activation of energy metabolism is the key process in the prevention of hepatosis, including fat. This aspect has determined the possibility of using succinic acid separately or in the 
form of succinates. Succinic acid (SA) administered exogenously, even in absolutely low dosages, nevertheless, provides an atypically high metabolic effect. Particularly, the oxygen consumption of liver cells increased 60 times [13]. The effect of low doses of succinic acid with alimentary acidosis and ketosis was discovered in the 70 s by M. N. Kondrashova [13, 14]. The effectiveness of sodium succinate and ammonium usage for the relief of metabolic acidosis is shown in numerous studies of scientists of the Institute of Biophysics of the USSR, Russia [11, 13-15]. In the course of clinical observations, the cows of the control group began to show a tendency to decreased appetite and milk productivity. Control biochemical tests of blood of these cows revealed profound changes. The alkali reserve index varied in the range of $15-17 \mathrm{mmol} / \mathrm{L}$ (metabolic acidosis); the glucose level was 1.8-2.1 (energy deficit).

Table 1. Polymer medications effect on the biochemical status of cows of the first experimental group (iodinol in combination with SA).

\begin{tabular}{|c|c|c|c|c|}
\hline \multirow{2}{*}{ Parameters } & \multirow{2}{*}{ Normal range } & \multicolumn{3}{|c|}{ Days of the study } \\
\hline & & 2-3 days before fawning & 15 days after fawning & 30 days after fawning \\
\hline Total protein, g/l & $70-85$ & $82.8 \pm 2.4$ & $81.6 \pm 2.9$ & $81.4 \pm 2.8$ \\
\hline Glucose, mmol/l & $2.2-3.3$ & $2.2 \pm 0.02$ & $2.5 \pm 0.04$ & $2.8 \pm 0.04$ \\
\hline Triacylglycerol, mmol/l & $0.17-0.5$ & $1.22 \pm 0.24$ & $2.46 \pm 0.14$ & $2.04 \pm 0.17$ \\
\hline Alkali reserve, mmol/l & $19-27$ & $18.94 \pm 1.98$ & $23.62 \pm 1.75$ & $25.43 \pm 1.19$ \\
\hline Total bilirubin, $\mu \mathrm{mol} / 1$ & $0.2-5.1$ & $7.26 \pm 0.34$ & $8.41 \pm 0.76$ & $7.29 \pm 0.87$ \\
\hline Ketone bodies, $\mathrm{mmol} / \mathrm{l}$ & $0.3-1.2$ & $1.1 \pm 0.04$ & $1.3 \pm 0.01$ & $1.1 \pm 0.02$ \\
\hline $\begin{array}{c}\mathrm{T}-3, \\
\mathrm{nmol} / 1\end{array}$ & 2.6-3.0 (for healthy) & $2.31 \pm 0.47$ & $4.37 \pm 0.52$ & $8.32 \pm 0.51$ \\
\hline $\begin{array}{c}\mathrm{T}-4, \\
\mathrm{nmol} / \mathrm{l}\end{array}$ & $\begin{array}{c}37-43 \\
\text { (for healthy) }\end{array}$ & $32.7 \pm 2.98$ & $34.9 \pm 2.57$ & $43.5 \pm 3.05$ \\
\hline
\end{tabular}

The level of thyroid hormones Triiodothyronine (T3 ) is $0.7-0.9 \mathrm{nmol} / 1$ (for clinically healthy animals $-2.6-$ 3.0). Thyroxine (T-4) is $16-22 \mathrm{nmol} / 1$ (for clinically healthy animals - 37-43) in relation to clinically healthy individuals it would be 2-3 times lower, which indicated a pronounced iodine deficiency.

In 20-25 days after fawning, the hair of the control group cows acquired a dull appearance. Hair began to fall out intensively in the neck area; the skin became dry, rough, and folded. These are typical clinical signs of iodine deficiency.

Similar clinical, but less obvious symptoms began to appear in some cows that were injected with pharmacopoeial iodinol.

The cows of the first experimental group had a qualitatively different clinical status (iodinol was tested in combination with succinic acid). This group of cows had a well-expressed tendency to milk productivity increase. The body hair was smooth and shiny.

When studying the effect of the tested medications on the metabolic processes of cows, the following dynamics of biochemical parameters was established. It is indicated in the tables below for clarity.

Table 2. Polymer medications effect on the biochemical status of cows of the second experimental group (pharmacopoeial iodinol).

\begin{tabular}{|c|c|c|c|c|}
\hline \multirow{2}{*}{ Parameters } & \multirow{2}{*}{ Normal range } & \multicolumn{3}{|c|}{ Days of the study } \\
\cline { 3 - 5 } & 2-3 days before fawning & 15 days after fawning & 30 days after fawning \\
\hline Total protein, g/l & $70-85$ & $82.5 \pm 2.3$ & $84.3 \pm 2.6$ & $87.3 \pm 3.1$ \\
\hline Glucose, mmol/l & $2.2-3.3$ & $2.3 \pm 0.03$ & $2.4 \pm 0.03$ & $2.3 \pm 0.03$ \\
\hline Triacylglycerol, mmol/l & $0.17-0.5$ & $1.26 \pm 0.31$ & $2.28 \pm 0.17$ & $2.25 \pm 0.21$ \\
\hline Alkali reserve, $\mathrm{mmol} / 1$ & $19-27$ & $19.07 \pm 1.84$ & $18.51 \pm 1.21$ & $19.34 \pm 1.22$ \\
\hline Total bilirubin, $\mu \mathrm{mol} / 1$ & $0.2-5.1$ & $7.29 \pm 0.32$ & $9.04 \pm 0.68$ & $9.75 \pm 1.03$ \\
\hline Ketone bodies, $\mathrm{mmol} / 1$ & $0.3-1.2$ & $1.1 \pm 0.03$ & $1.4 \pm 0.2$ & $6.02 \pm 0.32$ \\
\hline $\begin{array}{c}\mathrm{T}-3, \\
\mathrm{nmol} / \mathrm{l}\end{array}$ & $\begin{array}{c}2.6-3.0 \\
\text { for healthy) }\end{array}$ & $2.36 \pm 0.42$ & $3.25 \pm 0.24$ & $29.4 \pm 1.95$ \\
\hline $\begin{array}{c}\mathrm{T}-4, \\
\mathrm{nmol} / \mathrm{l}\end{array}$ & $\begin{array}{c}37-43 \\
\text { for healthy) }\end{array}$ & $31.6 \pm 2.87$ & $21.7 \pm 1.02$ & 6.04 \\
\hline
\end{tabular}


Table 3. Polymer medications effect on the biochemical status of cows of the control group.

\begin{tabular}{|c|c|c|c|c|}
\hline \multirow{2}{*}{ Parameters } & \multirow{2}{*}{ Normal range } & \multicolumn{3}{|c|}{ Days of the study } \\
\hline & & 2-3 days before fawning & 15 days after fawning & 30 days after fawning \\
\hline Total protein, $\mathrm{g} / \mathrm{l}$ & $70-85$ & $83.1 \pm 2.3$ & $89.5 \pm 3.3$ & $95.2 \pm 4.6$ \\
\hline Glucose, $\mathrm{mmol} / \mathrm{l}$ & $2.2-3.3$ & $2.3 \pm 0.02$ & $2.2 \pm 0.03$ & $1.8 \pm 0.02$ \\
\hline Triacylglycerol, mmol/l & $0.17-0.5$ & $1.25 \pm 0.37$ & $4.72 \pm 0.23$ & $4.75 \pm 0.19$ \\
\hline Alkali reserve, mmol/l & $19-27$ & $19.14 \pm 1.79$ & $16.12 \pm 0.98$ & $15.17 \pm 1.01$ \\
\hline Total bilirubin, $\mu \mathrm{mol} / \mathrm{l}$ & $0.2-5.1$ & $7.03 \pm 0.23$ & $9.52 \pm 0.94$ & $11.34 \pm 1.21$ \\
\hline Ketone bodies, $\mathrm{mmol} / \mathrm{l}$ & $0.3-1.2$ & $1.1 \pm 0.04$ & $2.8 \pm 0.03$ & $3.7 \pm 0.08$ \\
\hline $\begin{array}{c}\mathrm{T}-3, \\
\mathrm{nmol} / \mathrm{l}\end{array}$ & $\begin{array}{c}2.6-3.0 \\
\text { (for healthy) }\end{array}$ & $2.26 \pm 0.23$ & $1.34 \pm 0.32$ & $1.02 \pm 0.37$ \\
\hline $\begin{array}{c}\mathrm{T}-4, \\
\mathrm{nmol} / \mathrm{l}\end{array}$ & $\begin{array}{c}37-43 \\
\text { (for healthy) }\end{array}$ & $31.9 \pm 2.89$ & $21.7 \pm 1.02$ & $19.2 \pm 1.52$ \\
\hline
\end{tabular}

The initial biochemical status of the cows indicated that the level of total protein, triacylglycerol, and total bilirubin were mostly above the upper limit of physiological values. The glucose level is within the lower limit. The level of alkali reserve is lower than physiological values (metabolic acidosis).

The most obvious changes in the biochemical status of experimental cows of the compared groups appeared on the 15th day after fawning. At the same time, the cows of the first experimental group, on which iodinol was tested in combination with succinic acid, had the level of protein and glucose content within the average physiological values. This shows that the energy processes of fat oxidation in the liver proceed without any deviations. This is obvious by the low levels of ketone bodies. The usage of pharmacopoeial iodinol among cows of the second group did not have such an obvious metabolic effect. All biochemical parameters of the animals of this group were either at the lower level (glucose, alkali reserve) or at the upper level (total bilirubin, ketone bodies) of physiological values. During this period, the values of cows of the control group deviated from the physiological values. This is due to the active involvement of the body's own lipids in the process of metabolism. It is indicated by an intensive increase of ketone bodies and the triacylglycerol level.

On the $30^{\text {th }}$ day, the cows of the first and the second experimental groups showed the stabilization of biochemical parameters. On the contrary, the cows of the control group had a $20-30 \%$ higher level of total protein, lipids, bilirubin, and ketone bodies than that of the physiological values. The level of glucose (energy deficit) was below the normal level.

\section{Conclusion}

Summarizing the results of clinical observations and biochemical studies, we can draw the following conclusions:

- application of iodinepolymer medications on highly productive cows is of practical interest for the metabolism correction at risk of pathobiochemical processes development during protein over-feeding, intensive involvement of own body lipids in energy processes, and increasing release of iodine from milk;

- the iodine composition "Iodinol" based on the biopolymer in combination with the hepatoprotective metabolite succinic acid can be referred to the energymetabolic preparation with potentially high universal anti-infective activity by the mechanism of action.

\section{References}

1. S.L. Boroznov, A.A. Matsinovich, Uchenye zapiski UO VGAVM, E 42, 143 (2006)

2. V.A. Mishchenko, A.V. Mishchenko, V.V. Dumova, I.V. Ermilov, Veterinary Medicine of Kuban, 6 (2012)

3. S.N. Turnaev, Al.A. Yevglevsky, Bulletin of Kursk State Agricultural Academy, E 9, 69 (2014)

4. Al.A. Yevglevsky, V.N. Skira, G.F. Ryzhkova, I.I. Mikhailova, Bulletin of Russian Agricultural Science, E 2, 68 (2019)

5. A. Z. Shantyz Prospects for the use of iodinecontaining drugs in veterinary medicine. Abstract of the dis. d. v. n. Krasnodar - 2015.

6. N. Bader, U. Möller, M. Leiterer, K. Franke, and G. Jahreis, Investigations in Jena/Thuringia, (2003)

7. L.B. Rasmussen, Rasmussen, L. Ovesen, I. Bulou, T. Jorgensen, N. Knudsen, P. Laurberg, H. Perrild, Lone British Journal of Nutrition, E 87, 67 (2002)

8. E.N. Pearce, S. Pearce, X. Pino, H.R. He, S.L. Bazrafshan, L.E. Lee, Braverman, Boston area Journal of clinical Endocrinology and metabolism, E 89(7), 3420 (2004)

9. G. Jahreis, M. Leather, K. France, W. Maichrowitz, F. Schone, V. Hesse, Kinderpraxis, E 16, 179 (1999)

10. V.O. Mokhnach, A.B. Waldman, P.D. Evdokimov, Nauka, E 3, 187 (1967)

11. Yu. Yu. Ivnitsky, A. Golovko, G.A. Safronov, Succinic acid in the system of means of metabolic 
correction of the functional state of the body resistance (St. Petersburg, Bian, 1998)

12. E.V. Dushkin, Fatty liver in dairy cows (Methodological Guide, Krasnodar, 2012)

13. M. N. Kondrashova, M. R. Chkalovets, Reports of the USSR Academy of Sciences, E 1. 25 (1971)

14. M. N. Kondrashova, Pushchino, E 4, 270 (1976)

15. M. N. Kondrashova, Pushchino, E 4, 234 (1976)

16. E.I. Mayevsky, Russian Biomedical Journal Medline.ru. E 2, 19, 114 (2001) 